\title{
Modification of soybean sucrose synthase by S-thiolation with ENOD40 peptide A
}

\author{
Horst Röhrig ${ }^{1}$, Michael John, Jürgen Schmidt* \\ Max-Planck-Institut für Züchtungsforschung, Carl-von-Linné-Weg 10, 50829 Cologne, Germany \\ Received 7 October 2004 \\ Available online 5 November 2004
}

\begin{abstract}
The gene ENOD40 is expressed at an early stage of root nodule organogenesis and has been postulated to play a central regulatory role in the Rhizobium-legume interaction. In vitro translation of soybean ENOD40 mRNA showed that the gene encodes two peptides of 12 and 24 aa residues (peptides A and B) that bind to sucrose synthase. Here we show that the small Cys-containing peptide A binds to sucrose synthase by disulfide bond formation, which may represent a novel form of posttranslational modification of this important metabolic enzyme. Assays using nanomolar concentrations of peptide A revealed that the monomeric reduced form of this peptide binds to purified sucrose synthase. Using a cysteinyl capture strategy combined with MALDI-TOF MS analysis we identified the Cys residue C264 of soybean sucrose synthase as the binding site of peptide A. Modification of sucrose synthase with ENOD40 peptide A activates sucrose cleavage activity whereas the synthesis activity of the enzyme is unaffected. The results are discussed in relation to the role of sucrose synthase in the control of sucrose utilization in nitrogen-fixing nodules.
\end{abstract}

(C) 2004 Elsevier Inc. All rights reserved.

Keywords: Plant peptide; Disulfide bond formation; Mixed disulfides; Covalent modification; Protein activity

The symbiotic interaction between leguminous plants and rhizobia results in the development of the nodule, a new organ on plant roots. In these nodules the bacteria are hosted intracellularly as bacteroids and find the ideal environment to fix atmospheric nitrogen. Nitrogen fixation is an energy-demanding process which is dependent on the supply of photosynthate. Sucrose, as the major end product of photosynthesis, is synthesized in leaves and is transported in the phloem to various sink tissues such as nodules. This disaccharide is cleaved by the homotetrameric enzyme sucrose synthase (SuSy) catalyzing the reversible, UDP-dependent cleavage of sucrose into UDP-glucose and fructose. This reaction is considered to function in vivo in the sucrose breakdown

\footnotetext{
${ }^{*}$ Correspondence author. Fax: +49 2215062213.

E-mail address: jschmidt@mpiz-koeln.mpg.de (J. Schmidt).

${ }^{1}$ Present address: Botanisches Institut, Universität Bonn, Kirschallee 1, 53115 Bonn, Germany.
}

direction providing substrates for rapidly growing tissues and sink organs. SuSy is one of the most abundant proteins in mature legume nodules [1,2], and breakdown of sucrose is a key step in nitrogen fixation and a necessary prerequisite for normal nodule development and function [3].

Due to the important role of SuSy in the control of sucrose utilization in sink tissues, the expression of SuSy genes is highly regulated on the transcriptional and translational levels [4]. Moreover, SuSy is posttranslationally modified by reversible protein phosphorylation $[5,6]$, and the soluble form of SuSy can bind to the actin cytoskeleton in plants [7]. Recently, we reported direct binding of SuSy to peptide A (12 aa residues) and peptide $\mathrm{B}$ ( 24 aa residues) encoded by the early nodulin gene ENOD40 [8]. In addition to the two small peptides, the secondary structure of ENOD40 mRNA has been shown to be a key element in the signaling process underlying nodule organogenesis $[9,10]$. 
The plant gene ENOD40 is one of the earliest nodulin genes specifically induced by nodulation factor-secreting rhizobia and appears to play an important role in root nodule organogenesis. Expression of this gene is not confined to nodules, because ENOD40 transcripts have been detected also in non-symbiotic tissues, such as developing lateral roots [11-13], young leafs [11], and stem cells $[11,14,15]$. In situ hybridization studies revealed that ENOD40 transcripts accumulate in vascular bundles of mature plant organs, mainly at sites of intensive lateral transport, suggesting a role in vascular tissue function [14-16]. ENOD40 homologs have also been identified in the non-legumes tobacco [17] and rice [18] indicating a more general role in plants.

These data together with our recent finding that ENOD40 encoded peptides bind to SuSy [8] suggest that these short translation products are involved in the control of sucrose utilization in nitrogen-fixing nodules.

In this paper, we provide evidence that the small Cyscontaining peptide A binds to sucrose synthase by disulfide bond formation, which represents a novel form of posttranslational modification of this important metabolic enzyme. We also show that the sucrose cleaving activity but not the synthetic activity of SuSy is activated by protein S-thiolation with ENOD40 peptide A.

\section{Materials and methods}

Plant materials. Soybean plants (Glycine max cv. jutro) were grown and inoculated with Bradyrhizobium japonicum USDA 110 as described [8]. Nodules collected 4 weeks after inoculation were frozen in liquid nitrogen and stored at $-70{ }^{\circ} \mathrm{C}$.

Synthetic peptides. Peptide A (MELCWLTTIHGS), peptide B (MVLEEAWRERGVRGEGAHSSHSLT), and the peptide A analog Cys4 $\rightarrow$ Ser4 (C4S, MELSWLTTIHGS) were synthesized by Neosystem (Strasbourg, France). Peptides were labeled by coupling an additional biotinylated lysine residue to the $\mathrm{C}$-terminus of the sequence. Peptides were dissolved in a small volume of dimethyl sulfoxide (DMSO) and diluted with water to $20 \%$ DMSO. Intermolecular disulfide bond formation of peptide A was performed by mild oxidation with $20 \%$ DMSO as described [19]. Peptide A was completely reduced by treatment with $1 \mathrm{mM}$ DTT at $50{ }^{\circ} \mathrm{C}$ for $15 \mathrm{~min}$ and subsequently alkylated by a 15 -min incubation with $2.5 \mathrm{mM}$ iodoacetamide (Sigma) at room temperature. Alkylated peptide A and peptide A dimer were purified by RP-HPLC as described [8]. Purity of each peptide was assessed by HPLC and MALDI-TOF MS [20].

Preparation of antibodies. Abs directed against peptide A and SuSy were prepared as described recently [8]. Rabbit antisera were obtained from Neosystem. IgG fractions were prepared by purification on protein A-Sepharose (Amersham Biosciences). For the isolation of antigen-specific anti-SuSy and anti-peptide AbS, an affinity matrix was prepared by coupling either peptide A or SuSy to NHS-activated Sepharose (HiTrap, Amersham Biosciences). Purification of polyclonal Abs on these antigen columns was carried out as described [21].

Synthesis of radiolabeled peptide. ${ }^{35} \mathrm{~S}$-labeled peptide A was synthesized by in vitro translation of mutant soybean ENOD40 mRNA (mutant M1) in wheat germ extract in the presence of $\left[{ }^{35} \mathrm{~S}\right]$ methionine $(30 \mu \mathrm{Ci}$, Amersham Biosciences) and anti-peptide A Abs $(10 \mu \mathrm{g})$ as described [8]. Radiolabeled peptide was isolated by RP C18 solid-phase extraction (Vydac, Hesperia, CA, 218TPB13).
Purification of SuSy. Frozen nodules (1 g) were ground in liquid nitrogen and the powder was thawed in $10 \mathrm{ml}$ of extraction buffer containing $50 \mathrm{mM}$ Tris- $\mathrm{HCl}$ ( $\mathrm{pH} 7.5$ ), $10 \mathrm{mM} \mathrm{MgCl} 2,0.5 \mathrm{mM} \mathrm{CaCl}_{2}$, $1 \mathrm{mM}$ EDTA, $250 \mathrm{mM}$ sucrose, $5 \mathrm{mM}$ DTT, and protease inhibitors (Complete, EDTA-free, and bestatin, Roche Diagnostics). The suspension was homogenized at $4{ }^{\circ} \mathrm{C}$ with an Ultra-Turrax T8 (IKA, Staufen, Germany) and centrifuged for $20 \mathrm{~min}$ at $30,000 \mathrm{~g}$. Solid ammonium sulfate was added to the supernatant to a final concentration of $40 \%$ saturation. Proteins were precipitated overnight at $4{ }^{\circ} \mathrm{C}$ and fractionated on a Superdex 200 10/300GL column (Amersham Biosciences). The column was eluted with $20 \mathrm{mM}$ Tris- $\mathrm{HCl}$ ( $\mathrm{pH} \mathrm{8.0)}$, $10 \mathrm{mM} \mathrm{MgCl}$, and $200 \mathrm{mM} \mathrm{NaCl}$. The SuSy-containing fraction was collected and used directly for peptide-binding and enzyme assays. Protein concentrations were determined by the dye-binding assay (BioRad) with BSA as the standard.

Peptide-binding assays. Protease inhibitors and a detergent mix were added to the purified SuSy fraction to achieve a final concentration of $0.1 \%$ Nonidet P-40 and $0.05 \%$ deoxycholate. Incubations of SuSy with different peptides were carried out at $18{ }^{\circ} \mathrm{C}$ on a rotating wheel for $30-120 \mathrm{~min}$ as indicated in the legend of Fig. 1. Conditions for binding reactions with biotinylated peptide $\mathrm{A}$ and subsequent coupling to streptavidin-agarose beads (Pierce) were essentially the same as described [8]. Bound SuSy was released by heating the agarose beads in NuPAGE sample buffer (Invitrogen) for $20 \mathrm{~min}$ at $70^{\circ} \mathrm{C}$. Samples were separated on a NuPAGE Novex 4-12\% Bis-Tris gel in Mes-SDS running buffer (Invitrogen), and proteins were stained with SYPRO Ruby (Molecular Probes). Binding reaction mixtures containing SuSy and ${ }^{35}$ S-labeled peptide A or peptide A carrying no label were rechromatographed on a Superdex 200 10/300GL column. The SuSy-peptide A conjugate was isolated and the column buffer was replaced with $50 \mathrm{mM} \mathrm{NH} \mathrm{NHCO}_{3}$ using a PD-10 desalting column (Amersham Biosciences). After lyophilization the SuSy-peptide A conjugates were analyzed on NuPAGE Novex Bis-Tris gels. Radiolabeled peptide A was detected by autoradiography. Unlabeled peptide A bound to SuSy was electroblotted to a Sequi-Blot poly(vinylidene difluoride) membrane (Bio-Rad) using NuPAGE transfer buffer. The immobilized peptide A-SuSy conjugate was detected with affinity-purified anti-peptide A Abs followed by incubation with ${ }^{35} \mathrm{~S}$-labeled second Abs (Amersham Biosciences). Gels were calibrated with precision protein standards (Bio-Rad).

Sucrose synthase assays. SuSy activity was assayed spectrophotometrically at $340 \mathrm{~nm}$. For the determination of the cleavage activity (sucrose $+\mathrm{UDP} \rightarrow \mathrm{UDP}-\mathrm{Glc}+\mathrm{Fru})$ the reaction mixture $(1 \mathrm{ml})$ contained $20 \mathrm{mM}$ Hepes-KOH (pH 7.5), $5 \mathrm{mM} \mathrm{MgCl}_{2}, 200 \mathrm{mM}$ sucrose, $1.5 \mathrm{mM}$ UDP, and an appropriate amount of purified SuSy $(30 \mu \mathrm{g})$. After incubation at $30^{\circ} \mathrm{C}$ for $30 \mathrm{~min}$ the reaction was stopped by heating for $5 \mathrm{~min}$ in a boiling water bath. The amount of released Fru was measured enzymatically using the fructose assay kit (Sigma). Synthesis activity catalyzed by SuSy (Fru + UDP - Glc $\rightarrow$ UDP + sucrose) was measured in a reaction mixture $(1 \mathrm{ml})$ containing $20 \mathrm{mM}$ Hepes-KOH (pH 7.5), $5 \mathrm{mM} \mathrm{MgCl}_{2}, 15 \mathrm{mM}$ Fru, $2 \mathrm{mM}$ UDP-Glc, and SuSy protein $(30 \mu \mathrm{g})$. After 30 -min incubation at $30^{\circ} \mathrm{C}$ the reaction was stopped by heating and the amount of sucrose was measured enzymatically using the sucrose assay kit (Sigma). These assays were used to study the effects of different peptides on SuSy activity.

Cysteinyl peptide capture. Purified SuSy $(500 \mu \mathrm{g})$ was incubated on a rotating wheel $\left(16 \mathrm{~h}\right.$ at $\left.18{ }^{\circ} \mathrm{C}\right)$ with biotinylated peptide $\mathrm{A}(50 \mu \mathrm{g})$ or with mutated biotinylated peptide $\mathrm{A}(\mathrm{C} 4 \mathrm{~S})$ as control in a buffer containing $20 \mathrm{mM}$ Tris- $\mathrm{HCl}$ ( $\mathrm{pH} \mathrm{8.0),} 10 \mathrm{mM} \mathrm{MgCl}_{2}, 200 \mathrm{mM} \mathrm{NaCl}$, and protease inhibitors. To remove non-covalently bound peptide, the incubation mixture was rechromatographed on a Superdex 200 10/

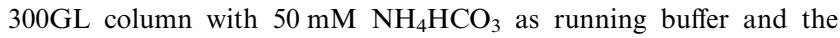
collected protein was lyophilized. The protein was then dissolved in $0.1 \mathrm{M} \mathrm{NH}_{4} \mathrm{HCO}_{3}$, alkylated by a 15 -min incubation with $5 \mu \mathrm{l}$ of $0.2 \mathrm{M}$ iodoacetamide and digested with $25 \mu \mathrm{g}$ trypsin (Roche Diagnostics) for $20 \mathrm{~h}$ at $37^{\circ} \mathrm{C}$. Residual tryptic activity was inhibited by adding TLCK$\mathrm{HCl}$, antipain-2 $\mathrm{HCl}$, and leupeptin (Roche Diagnostics) to the digest. 
To capture the cysteinyl target peptide, $20 \mu \mathrm{l}$ of streptavidin-agarose beads was added and the mixture was tumbled for $30 \mathrm{~min}$ at $18^{\circ} \mathrm{C}$. The beads were first washed five times with a buffer containing $0.1 \mathrm{M}$ $\mathrm{NH}_{4} \mathrm{HCO}_{3}, 0.5 \mathrm{M} \mathrm{NaCl}, 0.1 \%$ Nonidet $\mathrm{P}-40,0.05 \%$ sodium deoxycholate, and finally with $50 \mathrm{mM} \mathrm{NH} \mathrm{NHCO}_{3}$. To elute the retained cysteinyl peptide the beads were suspended in $20 \mu \mathrm{l}$ of $50 \mathrm{mM}$ $\mathrm{NH}_{4} \mathrm{HCO}_{3}$ containing $1 \mathrm{mM}$ DTT and incubated for $20 \mathrm{~min}$ at $50{ }^{\circ} \mathrm{C}$. After reduction of the disulfide bonds the sulfhydryl-groups were alkylated with $2 \mathrm{mM}$ iodoacetamide for $20 \mathrm{~min}$ and subsequently $1 \mu \mathrm{l}$ of $10 \%$ trifluoroacetic acid (TFA) was added. Peptides were desalted and concentrated using $\mathrm{C}_{18}$ ZipTips (Millipore). The sample was mixed with an equal volume of a saturated solution of $\alpha$-cyano-4-hydroxycinnamic acid (HCCA, Bruker) in 50\% acetonitrile $/ 0.1 \%$ TFA. Mass spectra of tryptic peptides were taken with a Bruker Reflex IV matrixassisted laser desorption ionization-time of flight mass spectrometer (MALDI-TOF MS). Peptide identity was further confirmed by postsource-decay (PSD) analysis including the subsequent assignment of the fragment masses using BioTools 2.0 (Bruker) and a MASCOT database search.

\section{Results}

\section{Peptide A binds to SuSy by disulfide bond formation}

Recently, we reported that the soybean ENOD40 gene encodes two peptides that bind to SuSy. Peptide A contains a Cys residue that is highly conserved in legumes and conversion of this residue to Ser abolishes peptide A binding [8]. This suggests that the sulfhydryl group of the Cys residue may be involved in disulfide bonding. To test this, binding reactions of biotinylated peptide A with SuSy were performed in the absence or in the presence of $1 \mathrm{mM}$ DTT. Fig. 1A shows that the addition of the reductant DTT prevents binding of peptide A to SuSy. In addition, alkylation of the Cys residue with iodoacetamide blocking the free thiol group abrogated peptide A binding activity (Fig. 1A, lane 3). Moreover, binding of peptide A to SuSy could be detected with biotinylated peptide in the lower nanomolar range (data not shown).

In the course of the experiments it turned out that peptide $\mathrm{A}$ is sensitive to oxidation and can easily dimerize in solution. To answer the question whether the monomer or dimer of peptide A binds to SuSy, we oxidized biotinylated peptide A in 20\% DMSO and purified the dimer. Sucrose synthase binding assays using biotinylated monomer and dimer of peptide A indicate that the free sulfhydryl group of the peptide A monomer is responsible for binding to this enzyme (Fig. 1B).

To further explore whether the reduced form of peptide A binds covalently to SuSy forming a mixed disulfide, we used two approaches. First, we synthesized ${ }^{35}$ S-labeled peptide A and incubated this peptide with purified SuSy. The resulting radiolabeled conjugate was heat-treated in NuPAGE sample buffer containing either no reducing agent or $50 \mathrm{mM}$ DTT. SDS-PAGE under non-reducing conditions shows that the radiolabeled peptide is bound to SuSy and that this interaction cannot be disrupted by heat treatment (Fig. 2A, lane 1).

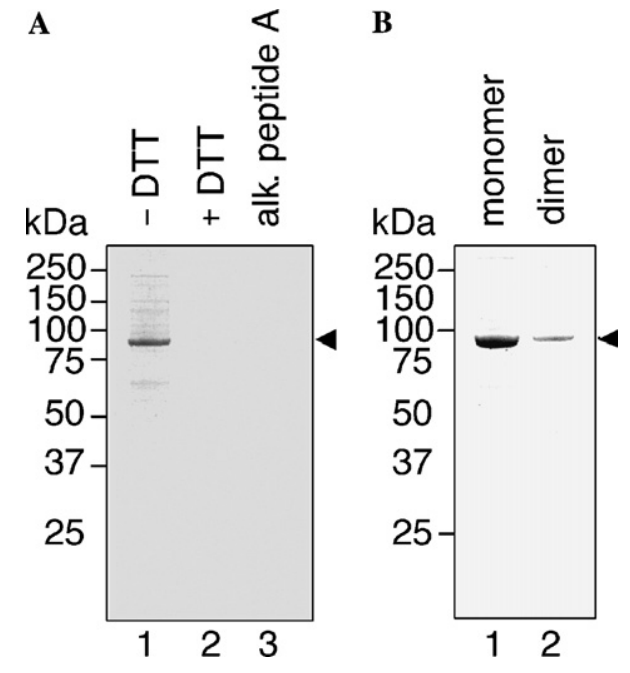

Fig. 1. Binding of GmENOD40 peptide A to SuSy. SuSy was purified from soybean nodules and samples of purified enzyme $(200 \mu \mathrm{g})$ were incubated with biotinylated peptides $(3 \mu \mathrm{M})$ in a total volume of $1 \mathrm{ml}$. The SuSy-peptide A complex was isolated with streptavidin-agarose beads and the compounds were eluted by heating the beads in NuPAGE sample buffer. Proteins were separated on a NuPAGE Novex $4-12 \%$ Bis-Tris gel and stained with SYPRO Ruby. (A) Biotinylated peptide A (lanes 1 and 2) was incubated with purified SuSy for $120 \mathrm{~min}$ in the absence (lane 1) or in the presence (lane 2) of $1 \mathrm{mM}$ DTT. Biotinylated peptide A in which the sulfhydryl group was alkylated with iodoacetamide was used as control (lane 3). (B) Binding of biotinylated peptide A monomer and dimer to SuSy. Incubations were carried out for $30 \mathrm{~min}$. Molecular mass markers are indicated in kiloDalton.

The minor band of free peptide A observed in the same lane apparently results from weak non-covalent binding of this peptide to SuSy. However, heat treatment in the presence of reducing agents like DTT completely releases the radiolabeled peptide (lane 2). As control, we have carried out binding studies with radiolabeled glutathione and SuSy from nodules. Using the same experimental conditions as described for peptide A no binding of glutathione to SuSy was observed (data not shown). Second, the intermolecular disulfide bond formation between peptide and SuSy was further analyzed by non-reducing SDS-PAGE, followed by immunoblot analysis using monospecific anti-peptide $\mathrm{Abs}$ and antiSuSy Abs as control. As shown in Fig. 2B (lane 2) the SuSy-peptide conjugate can be detected by anti-peptide A IgGs on the immunoblot only when the samples were heat-treated in the absence of DTT. However, treatment of the sample with DTT prior to immunoblot analysis disrupted the disulfide-linked SuSy-peptide conjugate so that anti-peptide A Abs did not detect a protein band at the expected molecular mass of $94 \mathrm{kDa}$ (lane 1).

\section{S-thiolation affects sucrose cleavage activity}

It has been postulated that S-thiolation is a reversible posttranslational modification of cysteine residues of 
A

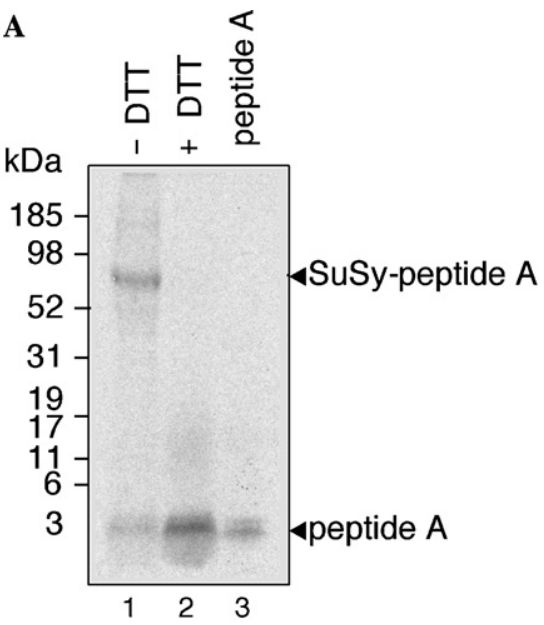

B anti-peptide A lgGs
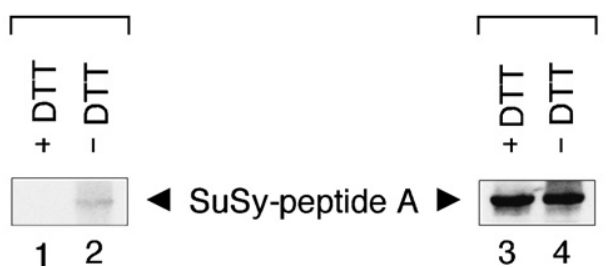

Fig. 2. Peptide A binds to SuSy by S-thiolation. (A) ${ }^{35}$ S-labeled peptide A was bound to SuSy. The resulting conjugate was heattreated in NuPAGE sample buffer containing either no reducing agent (lane 1) or $50 \mathrm{mM}$ DTT as reducing agent (lane 2). Proteins and peptides were separated on a NuPAGE Novex 4-12\% Bis-Tris gel with no antioxidant in the running buffer. Incorporation of radioactivity was detected by autoradiography. Molecular mass markers are indicated. (B) Immunoblot analysis of the SuSy-peptide A conjugate. The SuSy-peptide A conjugate was subjected to NuPAGE analysis with $50 \mathrm{mM}$ DTT (lanes 1 and 3 ) or without DTT (lanes 2 and 4 ) in the sample buffer. The conjugates were detected by Western blotting using polyclonal anti-peptide A or anti-SuSy antibodies.

proteins that can regulate protein activity. To test the effect of ENOD40 peptides on sucrose synthase activity, we incubated the purified enzyme for $1 \mathrm{~h}$ with different peptides prior to enzyme activity determination. Since SuSy catalyzes the cleavage and synthesis of sucrose, both activities were measured. When SuSy was incubated in the presence of $7 \mu \mathrm{M}$ peptide A, the ability to cleave sucrose was increased in all assays by approx. $20-30 \%$ compared to the non-treated control (Fig. $3 \mathrm{~A})$. On the other hand, another SuSy-binding ENOD40 peptide (peptide B) as well as a mutated version of peptide A (C4S) did not affect cleavage activity. In contrast, the synthesis activity of SuSy was not affected by incubation with peptide A (Fig. 3B). Moreover, when SuSy was incubated overnight with peptide $\mathrm{A}$ in the presence of molecular oxygen, we observed a ca. $50 \%$ higher cleavage activity compared to the control experiment in which the enzyme was not treated with this peptide (data not shown).
A
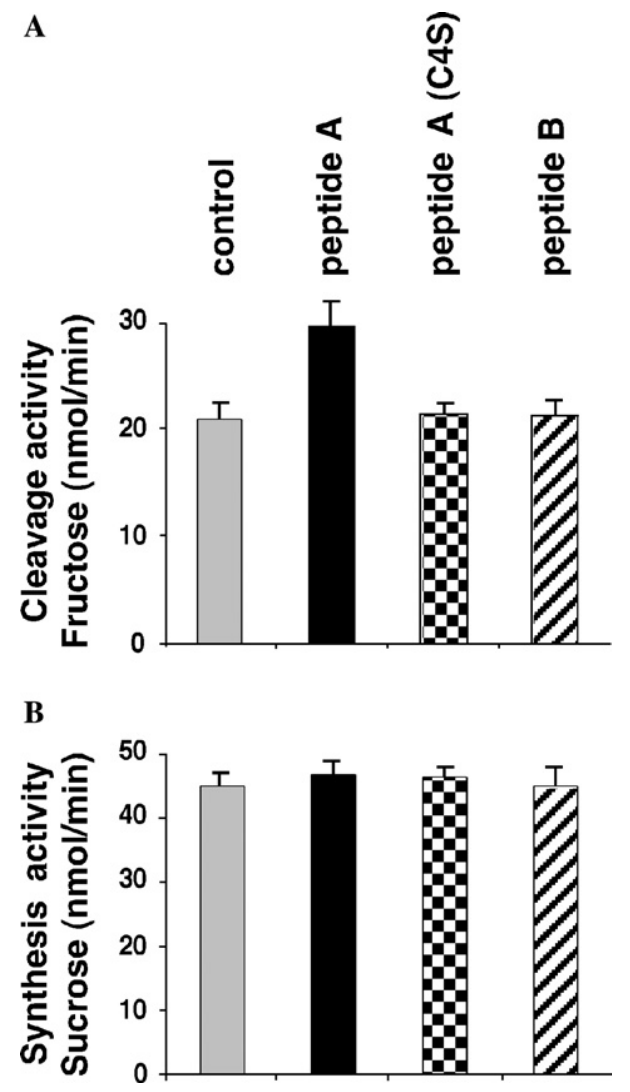

Fig. 3. Effect of ENOD40 peptides on sucrose synthase activity. Prior to activity determination the enzyme $(30 \mu \mathrm{g})$ was incubated with $7 \mu \mathrm{M}$ peptides for $1 \mathrm{~h}$ at $20^{\circ} \mathrm{C}$ in $1 \mathrm{ml}$ of $20 \mathrm{mM}$ Hepes-KOH (pH 7.5), $5 \mathrm{mM} \mathrm{MgCl}$ on a rotating wheel. As controls, incubations of SuSy without peptide A were performed. SuSy activity was determined in the cleavage (A) and synthesis (B) direction using a fixed-time assay followed by the enzymatic determination of fructose and sucrose. Data are means of three independent experiments performed in duplicate.

\section{Identification of the peptide A binding site}

In order to identify the Cys-containing target peptide from SuSy to which ENOD40 peptide A is covalently bound, we used a cysteinyl peptide capture strategy combined with MALDI-TOF MS analysis [20]. In these experiments purified SuSy was incubated with biotinylated peptide A or, as control, with biotinylated peptide A (C4S) in which Cys was replaced by Ser. To remove non-covalently bound peptide the incubation mixture was separated by gel chromatography and the collected biotinylated peptide A-SuSy conjugate was digested with trypsin. The tryptic SuSy fragment to which the biotinylated peptide A was coupled via disulfide bonds was then isolated with streptavidin-agarose beads. The retained cysteinyl peptide from SuSy was released from immobilized streptavidin with DTT and the free sulfhydryl group of cysteine was subsequently alkylated with iodoacetamide. MALDI-TOF analysis of the alkylated sample revealed a peptide mass at $2956.17 \mathrm{Da}$ corresponding to the tryptic peptide VLESIQLLLDLLEAP 


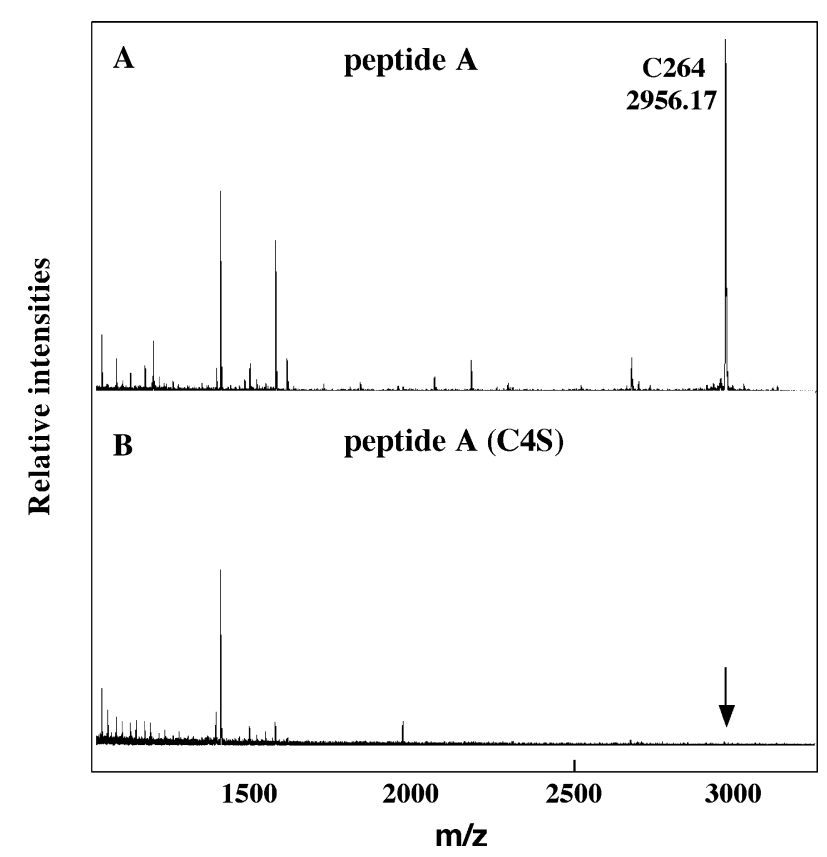

Fig. 4. MALDI-TOF MS identification of the Cys-containing target peptide from SuSy. (A) SuSy was S-thiolated with biotinylated peptide A and digested with trypsin overnight. (B) As control SuSy was incubated with a Cys $4 \rightarrow$ Ser4 (C4S) biotinylated analog of peptide A prior to trypsin digestion. The cysteinyl target peptide was then selectively captured by affinity purification using streptavidin-agarose beads. The retained cysteinyl peptide was eluted from the beads with DTT and subsequently alkylated with iodoacetamide. MALDI-TOF spectra were taken with a Bruker Reflex IV MALDI-TOF mass spectrometer using HCCA as matrix. The mass of the observed fragment differed from its theoretical value by less than $1 \mathrm{Da}$.

DPCTLETFLGR from soybean SuSy containing the alkylated cysteine residue C264 (Fig. 4A). This peptide fragment was not detectable in the control experiment performed with the mutated peptide $\mathrm{A}$ analog (C4S) lacking the cysteine residue (Fig. 4B). Peptide identity was confirmed by MALDI-PSD analysis of the selected peptide ion (data not shown).

\section{Discussion}

SuSy plays a major role in the degradation of sucrose in a variety of plant organs such as tubers, developing leaves, seeds, and root nodules. The activity of this enzyme is often correlated with the "sink strength" of these tissues [22], which is the ability of a sink organ to attract sucrose. In legume root nodules, hydrolysis of sucrose by SuSy is a key step in nitrogen fixation and deficient SuSy activity in nodules renders them incapable of effective nitrogen fixation $[3,23]$.

Recently, we have shown that peptide A is translated from a very short open reading frame of soybean ENOD 40 mRNA. Peptide A binds to SuSy and a Cys residue of this peptide, which is highly conserved in legumes, is essential for the interaction with this enzyme [8].
In this paper, several lines of evidence indicate that the cysteine sulfhydryl group of peptide A is responsible for disulfide bond formation with SuSy. First, assays using nanomolar concentrations of the monomer or dimer of peptide A revealed that the monomeric form of this peptide containing a free thiol group binds to SuSy. Second, addition of the reductant DTT to the binding reaction or alkylation of the free thiol group of the peptide with iodoacetamide prevents SuSy peptide A interaction. Third, radiolabeled peptide A could be released from the labeled conjugate by treatment with DTT. Fourth, Abs directed against peptide A recognized the peptide on the SuSy protein using immunoblot analysis. In addition, the cysteinyl peptide capture strategy combined with MALDI-TOF MS analysis identified the cysteine residue C264 as one of the 9 cysteines present in the soybean SuSy molecule as binding site of peptide A. The Cys 264 residue and the near-by sequences of SuSy are conserved in many plant species such as alfalfa, bean, grape, melon, orange, pea, potato, and tomato whereas Cys 264 is not present in SuSy of barley, carrot, and tobacco.

Since peptide A binds to SuSy in its monomeric reduced form, it is likely that a protein-SH group forms a mixed disulfide with the low-molecular-mass thiol. The formation of such a mixed disulfide is triggered under oxidizing conditions and this protein S-thiolation can be prevented in a reducing environment, e.g., by the presence of DTT in the binding reaction. This non-enzymatic posttranslational modification may lead to a conformational change of the SuSy protein that can affect enzyme activity.

It has been reported that SuSy activity is strongly inhibited by heavy metal ions [2] and can be modulated by redox agents [24] suggesting the involvement of thiol groups in the catalytic process. The $\mathrm{C} 264$ residue of SuSy, which became S-thiolated with the low-molecular-mass thiol peptide A, may belong to a reactive Cys which is particularly susceptible to oxidative modification. Thus, formation of a disulfide bond between SuSy and ENOD40 peptide A could be viewed as a protective mechanism that guards against the irreversible oxidation of the C264 residue of the enzyme. Our data also show that modification of SuSy by S-thiolation with peptide A activates sucrose cleavage activity whereas the synthesis activity of this enzyme remains unaffected, indicating that this covalent modification can regulate enzyme activity. Furthermore, it was recently demonstrated that binding of ENOD40 peptides to maize Susy protein antagonizes phosphorylation at Ser170 [6]. The authors propose that seryl-170 phosphorylation promotes SuSy degradation via the ubiquitin/proteasome pathway. Thus, binding of peptide A to SuSy may be a novel mechanism to enhance SuSy protein stability. 
Another well-known low-molecular-mass thiol is the tripeptide glutathione (GSH) which is abundant in plant cells. In soybean nodules a glutathione-related compound, homoglutathione, is the major tripeptide and functions in reduced form as an antioxidant. Such antioxidants play an important role in protecting and enhancing nitrogen fixation in nodules [25]. In contrast to ENOD40 peptide A, GSH is not translated, but its synthesis is catalyzed by enzymes. The thiol GSH is present in cells at millimolar concentrations and forms mixed disulfides with protein-SH groups, a modification which has been termed glutathionylation. Protein S-glutathionylation has been implicated in the buffering of oxidative stress, protection of proteins against irreversible oxidation of critical cysteine residues, and regulation of enzyme activity [26,27].

The formation of a mixed disulfide between C264 of SuSy and ENOD40 peptide A may be a mechanism to sense the redox status of the cells and may protect SuSy from oxidative inactivation in legume nodule. However, since this work was performed with purified enzyme, future studies will be necessary to show that S-thiolation of SuSy with peptide A is a novel form of posttranslational modification in vivo. Modification of this key metabolic enzyme, and functional responses like regulation of SuSy activity and protection of the protein against proteolysis, would lead to an increase in sink strength in nodules.

\section{Acknowledgments}

We dedicate this work to Jeff Schell, an outstanding and charismatic person, who vigorously supported our work until he passed away in April, 2003. We thank Ursula Wieneke for her continued excellent technical assistance and Gary Stacey (University of Missouri) for sending the Bradyrhizobium japonicum strain USDA110. We also thank Klaus Hahlbrock and George Coupland for critical reading of the manuscript.

\section{References}

[1] F. Thummler, D.P.S. Verma, Nodulin-100 of soybean is the subunit of sucrose synthase regulated by the availability of free heme in nodules, J. Biol. Chem. 262 (1987) 14730-14736.

[2] M. Morell, L. Copeland, Sucrose synthase of soybean nodules, Plant Physiol. 78 (1985) 149-154.

[3] A.J. Gordon, F.R. Minchin, C.L. James, O. Komina, Sucrose synthase in legume nodules is essential for nitrogen fixation, Plant Physiol. 120 (1999) 867-878.

[4] H. Winter, S.C. Huber, Regulation of sucrose metabolism in higher plants: localization and regulation of activity of key enzymes, Crit. Rev. Biochem. Mol. Biol. 35 (2000) 253289.

[5] O. Komina, Y. Zhou, G. Sarath, R. Chollet, In vivo and in vitro phosphorylation of membrane and soluble forms of soybean nodule sucrose synthase, Plant Physiol. 129 (2002) 1664 1673.

[6] S.C. Hardin, G.Q. Tang, A. Scholz, D. Holtgraewe, H. Winter, S.C. Huber, Phosphorylation of sucrose synthase at serine 170: occurrence and possible role as a signal for proteolysis, Plant J. 35 (2003) 588-603.

[7] H. Winter, J.L. Huber, S.C. Huber, Identification of sucrose synthase as an actin-binding protein, FEBS Lett. 430 (1998) 205208.

[8] H. Röhrig, J. Schmidt, E. Miklashevichs, J. Schell, M. John, Soybean ENOD40 encodes two peptides that bind to sucrose synthase, Proc. Natl. Acad. Sci. USA 99 (2002) 19151920.

[9] G. Girard, A. Roussis, A.P. Gultyaev, C.W.A. Pleij, H.P. Spaink, Structural motifs in the RNA encoded by the early nodulation gene enod40 of soybean, Nucleic Acids Res. 31 (2003) 50035015.

[10] A. Campalans, A. Kondorosi, M. Crespi, Enod40, a short open reading frame-containing mRNA, induces cytoplasmic localization of a nuclear RNA binding protein in Medicago trunctula, Plant Cell 16 (2004) 1047-1059.

[11] S. Asad, Y. Fang, K.L. Wycoff, A.M. Hirsch, Isolaton and characterization of cDNA and genomic clones of MSENOD40: transcripts are detected in meristematic cells of alfalfa, Protoplasma 183 (1994) 10-23.

[12] K. Papadopoulou, A. Roussis, P. Katinakis, Phaseolus ENOD40 is involved in symbiotic and non-symbiotic organogenetic processes: expression during nodule and lateral root development, Plant Mol. Biol. 30 (1996) 403-417.

[13] Y. Fang, A.M. Hirsch, Studying early nodulin gene ENOD40 expression and induction by nodulation factor and cytokinin in transgenic alfalfa, Plant Physiol. 116 (1998) 5368 .

[14] H. Kouchi, S. Hata, Isolation and characterization of novel nodulin cDNAs representing genes expressed at early stages of soybean nodule development, Mol. Gen. Genet. 238 (1993) 106119.

[15] E. Flemetakis, N. Kavroulakis, N.E.M. Quaedvlieg, H.P. Spaink, M. Dimou, A. Roussis, P. Katinakis, Lotus japonicus contains two distinct ENOD40 Genes that are expressed in symbiotic, nonsymbiotic, and embryonic tissue, Mol. Plant Microbe Interact. 13 (2000) 987-994.

[16] E. Varkonyi-Gasic, D.W. White, The white clover enod40 gene family. Expression patterns of two types of genes indicate a role in vascular function, Plant Physiol. 129 (2002) 1107-1118, Erratum in: Plant Physiol. (2002) 130, 514.

[17] M. Matvienko, K. van de Sande, K. Pawlowski, A. van Kammen, T. Bisseling, Biology of Plant Microbe Interactions, International Society for Molecular Plant Interactions, St. Paul (1996) 387 391.

[18] H. Kouchi, K. Takane, R.B. So, R.J.K. Ladha, P.M. Reddy, Rice ENOD40: isolation and expression analysis in rice and transgenic soybean root nodules, Plant J. 18 (1999) 121129.

[19] J.P. Tam, C.R. Wu, W. Liu, J.W. Zhang, Disulfide bond formation in peptides by dimethyl sulfoxide. Scope and application, J. Am. Chem. Soc. 113 (1991) 6657-6662.

[20] R.J. Simpson, Protein and Proteomics, Cold Spring Harbor Laboratory Press, Plainview, NY, 2003, pp. 520-523.

[21] E. Harlow, D. Lane, Using Antibodies, Cold Spring Harbor Laboratory Press, Plainview, NY, 1999.

[22] R. Zrenner, M. Salanoubat, L. Willmitzer, U. Sonnewald, Evidence of the crucial role of sucrose synthase for sink strength using transgenic potato plants (Solanum tuberosum L.), Plant J. 7 (1995) 97-107.

[23] J. Craig, P. Barratt, H. Tatge, A. Déjardin, L. Handley, C.D. Gardner, L. Barber, T. Wang, C. Hedley, C. Martin, A.M. Smith, 
Mutations at the rug4 locus alter the carbon and nitrogen metabolism of pea plants through an effect on sucrose synthase, Plant J. 17 (1999) 353-362.

[24] H.G. Pontis, J.R. Babio, G. Salerno, Reversible unidirectional inhibition of sucrose synthase activity by disulfides, Proc. Natl. Acad. Sci. USA 78 (1981) 6667-6669.

[25] M.A. Matamoros, D.A. Dalton, J. Ramos, M.R. Clemente, M.C. Rubio, M. Becana, Biochemistry and molecular biology of antioxidants in the rhizobia-legume symbiosis, Plant Physiol. 133 (2003) 499-509.

[26] D.M. Ziegler, Role of reversible oxidation-reduction of enzyme thiols-disulfides in metabolic regulation, Annu. Rev. Biochem. 54 (1985) 305-329.

[27] P. Klatt, S. Lamas, Regulation of protein function by Sglutathiolation in response to oxidative and nitrosative stress, Eur. J. Biochem. 267 (2000) 4928-4944. 